\title{
Time and Reality of Phenomenal Becoming
}

\author{
Sergio Galvan, Milan*
}

In the current debate on the nature of time one can identify two competing positions: the eternalist (B-series) and the Aristotelian (A-series) position. Which is the adequate one? I argue for the reality of becoming (A-series) on the basis of the experience, undeniable even for an eternalist, of the change of appearance in consciousness. I begin with formal characterizations of the A-theory and the B-theory on the general phenomenon of becoming. Then, I analyse the notion of change of appearing to consciousness. It turns out that it is not possible to provide an account of it in B-theoretical terms. For at least one state of affairs $\mathrm{p}$ of phenomenal nature it is certain that the reality of becoming is given: $\mathrm{A}$ (before, $\mathrm{p}) \wedge \neg \mathrm{A}$ (now, $\mathrm{p}$ ).

The tension in the contemporary philosophy of time between the A-theoretic conception (which ultimately derives from the Aristotelian theory of the ontic modalities) and the B-theoretic conception (with its strongly eternalist stance) is well known. The difference between the two conceptions in their interpretations of the temporal modalities originates from ultimate evidence to which appeal may be made but which does not provide sufficient grounds for deciding the legitimacy of one or the other. In other words, it is possible to argue against the eternalist conception on the basis of evidence-concerning the modality of being absolutely (i.e. not with respect to a world) actual-with which an eternalist would find it hard to agree. Vice versa, it is possible to argue against the Aristotelian theory of continuant objects on the basis of evidence that properties or subjects are indexed to worlds which a philosopher of Aristotelian inspiration would

* The author thoroughly discussed the content of this article with Edmund Runggaldier during his stay in Milan in March 2005, when he gave a course on analytic ontology in the philosophy of time at the Catholic University. In substantial accord with the content and technical formulation of the article, Runggaldier made a decisive contribution to its translation and to its presentation at the Wittgenstein Symposium of August 2005. The author is indebted to him for this and in particular for his assistance with the conference presentation. 
reject. Consequently, it does not seem that starting from evidence of this kind yields a solution to the problem.

However, although it is not possible to decide immediately between the eternalist and Aristotelian positions by resorting to ultimate evidence which both sides regard as conclusive, it may be possible to find a way to solve the problem mediately by starting from a common basis which both sides are bound to accept. This basis, I submit, is the original experience, undeniable even for an eternalist, of the inner becoming of consciousness. An eternalist usually responds to the observation that becoming is an immediate fact of which everyone has undeniable experience, not by denying this evidence but by restricting it to the sphere of the phenomenal. He says that becoming is a product of the knowing activity of the Self which creates within us the illusion of the real becoming of things, whereas belonging pertains only to the sphere of subjectivity.

To my knowledge, there has been no detailed analysis ${ }^{1}$ which clarifies whether becoming at the level of consciousness alone might be compatible with the base assumptions of the B-theory. The purpose of this paper is to conduct such analysis. It starts with the formal characterizations of the A-theory and the B-theory in relation to the general phenomenon of becoming. The second section analyses the becoming of consciousness (in the sense of appearing to the consciousness) and will seek to show that it is not possible to provide an account of it in B-theoretical terms.

\section{A-theoretic and B-theoretic analysis of becoming}

There are various ways to analyse the becoming of things. The two most significant and paradigmatic are the approaches typical of the A-theory and of the B-theory.

\section{A-theory}

I begin with the approach adopted by A-theorists. This interprets the becoming of an object as the set of different states in which the object successively finds itself-that is, the states of the object that are first to be actualized, are then actualized, and finally cease being actualized. Consider a simple case. Let a be an object and $\mathrm{F}$ a certain property. According to the

1 With the only exception of (Craig 2000a), 139-164, where the topic is not treated formally, though. 
A-theory, there is becoming if, for example, the two states $\mathrm{Fa}$ and $\neg \mathrm{Fa}$ succeed each other (i.e. are actualized in succession). Let us examine this initial intuition in formal terms.

Assume as given a classical propositional language (based on propositional letters like $\mathrm{p}$ or more complex statements like $\mathrm{Fa}$ ) and a set of temporal indices like $t, t^{\prime}, t^{\prime \prime}$. The temporal indices are conceivable as signs of worlds ordered by a relation $<$ (which is at least irreflexive, asymmetric and transitive). Let us introduce into this language an actualization operator $\mathrm{E}(\mathrm{t}, \mathrm{p})$ which expresses the fact that the state of affairs $\mathrm{p}$ is actual in $\mathrm{t}$. Note that this is an operator with two types of argument: the obvious argument of propositions (i.e. states of affairs) and the argument of the temporal indices. As regards the latter, the operator expresses the modal property of actual being external to individual temporal worlds and therefore absolute. Hence, because the notion of actuality expressed by $\mathrm{E}(\mathrm{p}, \mathrm{t})$ is absolute, it is possible to relate the temporal index $t$ to the 'now'. This relationship may arise in three ways: $1 . t$ coincides with 'now'; $2 . t<$ 'now'; or 3. 'now' $<\mathrm{t}$. Obviously, in case 1 . $\mathrm{E}(\mathrm{t}, \mathrm{p})$ means $\mathrm{E}$ (now,p) or 'p is actual now'; in case 2. $\mathrm{E}(\mathrm{t}, \mathrm{p})$ means $\mathrm{E}$ (before now,p) or 'p was actual'; in case 3 . $\mathrm{E}(\mathrm{t}, \mathrm{p})$ means $\mathrm{E}$ (after now,p) or ' $\mathrm{p}$ will be actual'. Thus, the tenses of present, past and future can be expressed by means of the operator $\mathrm{E}(\mathrm{t}, \mathrm{p})$. Finally to be noted is that the operator $\mathrm{E}(\mathrm{t}, \mathrm{p})$ behaves in classic manner like the truth operator, so that $\neg \mathrm{E}(\mathrm{t}, \mathrm{p})$ is equivalent to $\mathrm{E}(\mathrm{t}, \neg \mathrm{p})$.

Restricting the discussion to the case of changes in properties, we may say that a object changes in relation to the property $\mathrm{F}$ if there is a time $\mathrm{t}$ and $\mathrm{a}$ time $\mathrm{t}$ ' such that:

(1) $\mathrm{E}(\mathrm{t}, \mathrm{Fa}) \wedge \mathrm{E}\left(\mathrm{t}^{\prime}, \neg \mathrm{Fa}\right)$ (equivalently $\left.\mathrm{E}(\mathrm{t}, \mathrm{Fa}) \wedge \neg \mathrm{E}\left(\mathrm{t}^{\prime}, \mathrm{Fa}\right)\right)$.

And generally, with reference to any whatever state of affairs $p$, there is becoming if

(1) $\mathrm{E}(\mathrm{t}, \mathrm{p}) \wedge \mathrm{E}\left(\mathrm{t}^{\prime}, \neg \mathrm{p}\right)$ (equivalently $\mathrm{E}(\mathrm{t}, \mathrm{p}) \wedge \neg \mathrm{E}\left(\mathrm{t}^{\prime}, \mathrm{p}\right)$ ).

Note 1: (1) has a meaning that is not reducible in terms of a modal model and mere relation of order between the temporal indices (i.e. the worlds associated with them). That is to say, (1) does not coincide with $\left(1^{*}\right): \mathrm{t} \vDash \mathrm{Fa}$ and $\mathrm{t}^{\prime} \vDash \neg \mathrm{Fa}$ (for $\mathrm{t}<\mathrm{t}^{\prime}$ ). In fact, $\left(1^{*}\right)$ by no means entails the assumption that the worlds marked by the temporal indices are actualized in succes- 
sion (i.e. one after the other), The expression simply states that there exist two worlds, world $t$ and world $t^{\prime}$, related by a relation of order such that $\mathrm{Fa}$ is true in the first, while $\mathrm{Fa}$ is false in the second. It does not state that first world $\mathrm{t}$, in which $\mathrm{Fa}$ is true, was actual, and then that world ceased to be such, while world $\mathrm{t}^{\prime}$ in which $\neg \mathrm{Fa}$ is true became actual. In other words, something must be added to $\left(1^{*}\right)$ in order to obtain the meaning of (1). But what? We need a relation between worlds that is not a simple relation of order between modally non-different worlds but is rather a relation of order between modally different worlds. In other words, the relation should not be $\mathrm{t}<\mathrm{t}^{\prime}$ but $\mathrm{t}<_{\mathrm{a}} \mathrm{t}^{\prime}$, by which is meant that that world $\mathrm{t}$ has been actualized before $\mathrm{t}^{\prime}$. Likewise, $\mathrm{t}^{\prime}<_{\mathrm{a}} \mathrm{t}$ means that $\mathrm{t}$ will be actualized after $\mathrm{t}^{\prime}$, while $\mathrm{t}^{\prime}={ }_{\mathrm{a}} \mathrm{t}$ means that $\mathrm{t}^{\prime}$ is actualized at the same time as $\mathrm{t}$. In other words, $\mathrm{t}<_{\mathrm{a}} \mathrm{t}^{\prime}$ must entail that $t$ is actualized before $t^{\prime}$ and that the actualization of $t^{\prime}$ follows the cessation of $t$. Likewise in the other cases. Hence (1) is equivalent, not to $\left(1^{*}\right)$ but to $\left(1^{\prime}\right): \mathrm{t} \vDash \mathrm{Fa}$ and $\mathrm{t}^{\prime} \vDash \neg \mathrm{Fa}$ (for $\mathrm{t}<_{\mathrm{a}} \mathrm{t}^{\prime}$ ).

Note 2: also (1) presupposes, as said, a relation of temporal order. However, this is a purely formal relation of order (among co-actual instants), whilst it is the actualization operator $E$ which expresses the fact that the worlds marked by the temporal indexes $t$ and $t^{\prime}$ (where $t<t^{\prime}$ ) cannot be coactual; rather, the former has been actual before the latter has been. Consequently, $\mathrm{E}(\mathrm{t}, \mathrm{Fa}) \wedge \neg \mathrm{E}\left(\mathrm{t}^{\prime}, \mathrm{Fa}\right)$ (for $\left.\mathrm{t}<\mathrm{t}^{\prime}\right)$ has the same meaning as $\mathrm{t} \vDash \mathrm{Fa}$ and $\mathrm{t}^{\prime} \vDash \neg \mathrm{Fa}$ (for $\mathrm{t}<_{\mathrm{a}} \mathrm{t}^{\prime}$ ), which, in its turn, has the same meaning as the statement " $\mathrm{Fa}$, which is not actual in $\mathrm{t}^{\prime}$, has been actual in $\mathrm{t}$ ". It also follows that $\mathrm{E}(\mathrm{t}, \mathrm{Fa}) \wedge \mathrm{t}<$ now means "Fa has been actual".

\section{B-theory}

Of course, the analysis of becoming represented by (1) is based on the Atheoretical approach. But what is the analysis proposed by the B-theory? The B-theory keeps the content of $\left(1^{*}\right)$ and removes the dynamic and actualist character expressed by (1') and also contained in (1). This is justified by the eternalist metaphysics underpinning the B-theory. What do B-theorists think of the temporal indices? Some of them think that the properties of objects are semantically (and ontologically) dependent on temporal moments: for them, there is no property $\mathrm{F}$ in abstract, but as many $\mathrm{F}-\mathrm{in}-\mathrm{t}$ properties as there are temporal indexes. Others believe that indexication is preferably applied to objects. For these B-theorists, an object does not exist independently of the temporal moments in which it happens to find itself. To suppose that this object exists is to believe that it is always the same 
regardless of the temporal situation in which it happens to be. But this is impossible for the B-theorist. On the contrary, rather than the same object at different instants, there exists a series of similar a-in-t objects for every temporal instant $t$. Within the spirit of the B-theory one may also conceive both properties and objects as indicized (to the same index). Shared by both these positions is the fact that some of the entities implicated in the state of affairs are not independent from the temporal instant. The temporal index is an integral part of predicates or objects, or both. Thus, according to this analysis, the being $\mathrm{F}$ of $\mathrm{a}$ in $\mathrm{t}$ should not be understood as the being actual of the state of affairs $\mathrm{Fa}$ in $\mathrm{t}$ (i.e. formally $\mathrm{E}(\mathrm{t}, \mathrm{Fa})$ ), because this state of affairs does not exist semantically (and ontologically) independently of $t$. It should rather be understood as the being actual-in-t of $\mathrm{Fa}\left(\mathrm{E}_{\mathrm{t}}(\mathrm{Fa})\right)$, in the form of being $F$-in- $t$ of a $\left(F_{t} a\right)$ or the being $F$ of a-in- $t\left(F_{t}\right)$ or the being F-in- $t$ of a-in- $t\left(F_{t} a_{t}\right)$. Thus the state of affairs $F_{t} a\left(\right.$ or $F a_{t}$ or $\left.F_{t} a_{t}\right)$, of which the actuality is declared, is a part (the part in $t$ ) of the overall state of affairs Fa constituted by all the other states of affairs - if these exist $-\mathrm{F}_{\mathrm{t}^{\prime}} \mathrm{a}$ (or $\mathrm{Fa}_{\mathrm{t}^{\prime}}$ or $\left.F_{t^{\prime}} a_{t^{\prime}}\right)$ for $t^{\prime} \neq t$. In short, for $B$-theorists the being actual in $t, t^{\prime}, t^{\prime \prime} \ldots$ of the state of affairs $\mathrm{Fa}$ is not expressed by the series of expressions $\mathrm{E}(\mathrm{t}, \mathrm{Fa})$, $\mathrm{E}\left(\mathrm{t}^{\prime}, \mathrm{Fa}\right), \mathrm{E}\left(\mathrm{t}^{\prime \prime}, \mathrm{Fa}\right), \ldots-$ - where the actuality operator $\mathrm{E}$ is abstractly the same -, but by the series of expressions $\mathrm{E}_{\mathrm{t}}(\mathrm{Fa}), \mathrm{E}_{\mathrm{t}^{\prime}}(\mathrm{Fa}), \mathrm{E}_{\mathrm{t}^{\prime \prime}}(\mathrm{Fa}), \ldots$ each of which is characterized by a different indicized actuality operator. The meaning does not change if the state of affairs internal to the operator is itself indicized (of course, if the index is maintained the same). An alternative written form which maintains the same meaning is to use the atemporal actuality operator $\mathrm{E}$ and indicize only the state of affairs. Formally:

\begin{tabular}{|l|l|l|l|l|l|}
\hline & & $F_{t} a$ & $\begin{array}{l}\text { Being F-in- } t \\
\text { of } a\end{array}$ & $E_{t}(F a)_{t}$ & Being-in- $t$ of $(F a)-i n-t$ \\
\hline$E_{t}(F a)$ & $\begin{array}{l}\text { Being-in- } t \\
\text { of } F a\end{array}$ & $F_{t} a_{t}$ & $\begin{array}{l}\text { Being F-in- } t \text { of } \\
\text { a-in- } t\end{array}$ & E(Fa) $)_{t}$ & Being of $(F a)-i n-t$ \\
\hline & $F_{t}$ & $\begin{array}{l}\text { Being } F \text { of } a- \\
\text { in- } t\end{array}$ & & \\
\hline
\end{tabular}

In general:

\begin{tabular}{|l|l|l|l|l|}
\hline$E_{t} p$ & Being-in-t of $p$ & $p_{t}$ & $\begin{array}{l}E_{t}\left(p_{t}\right) \\
E\left(p_{t}\right)\end{array}$ & $\begin{array}{l}\text { Being-in- } t \text { of } p-i n-t \\
\text { Being of } p-i n-t\end{array}$ \\
\hline
\end{tabular}


To conclude, the B-theoretical analysis of becoming is as follows:

(2) $\mathrm{E}_{\mathrm{t}}(\mathrm{Fa}) \wedge \mathrm{E}_{\mathrm{t}^{\prime}}(\neg \mathrm{Fa})$ (equivalently $\left.\mathrm{E}_{\mathrm{t}}(\mathrm{Fa}) \wedge \neg \mathrm{E}_{\mathrm{t}^{\prime}}(\mathrm{Fa})\right)$.

And, in general, with reference to any whatever state of affairs $\mathrm{p}$ :

(2) $\mathrm{E}_{\mathrm{t}} \mathrm{p} \wedge \mathrm{E}_{\mathrm{t}^{\prime}}(\neg \mathrm{p})$ (equivalently $\mathrm{E}_{\mathrm{t}} \mathrm{p} \wedge \neg \mathrm{E}_{\mathrm{t}^{\prime}} \mathrm{p}$ ).

Note 1: Note that $\mathrm{p}_{\mathrm{t}}$ is a nominal, i.e. it is a proposition true in only one instant-world, this being precisely $t$.

Note 2: The above analysis of the indicized character of the B-theory's expressions highlights their eternalist meaning. This unequivocally results from the equivalence between $\mathrm{E}_{\mathrm{t}} \mathrm{p}$ and $\mathrm{E}_{\mathrm{t}}$. In the latter expression, in fact, the operator E states-precisely because it is not indicized-that the indicized fact $\mathrm{p}_{\mathrm{t}}$ exists in a sort of timeless actuality. The being of the temporalized state of affairs $\mathrm{p}_{\mathrm{t}}$ is eternally actual. This is because it does not make sense to attribute to individual worlds an external actuality that has been or will be. External actuality is distributed to the same extent among all worlds, which are all externally actual.

Note 3: The atemporal actuality expressed by the non-indicized operator E treated in the previous note implicates necessity in the form of actuality in all the instants-worlds. That is, the following modal law of necessity implication holds:

$\mathrm{EN}: \quad \mathrm{Ep}_{\mathrm{t}} \rightarrow \forall \mathrm{t}^{\prime} \mathrm{E}\left(\mathrm{t}^{\prime}, \mathrm{p}_{\mathrm{t}}\right)$

\section{The problem of phenomenal becoming}

The B-theoretical analysis is particularly cogent. Its merits are the simplicity of its base monomodal assumption and its robust inner coherence. However, it is obliged to address the problem of the experience of becoming. The most obvious way to deal with this problem is to assert the subjectivity of becoming. Becoming does not pertain to ontology (it is not an ontological phenomenon); rather, it is a phenomenon generated by consciousness. What is meant by this has not been sufficiently clarified by scholars. It is sometimes said that the experience of becoming is illusory, owing to the fact that it is generated by the consciousness and is therefore not grounded in reality. Indeed, it is true that particular aspects relative to the Self are 
illusory. For example, there may appear to the consciousness states of affairs to which nothing real corresponds $(A(x, p)$ does not necessarily entail $\mathrm{p})$. These states of affairs are certainly illusory, therefore. But this does not mean that $A(x, p)$ and $p$ does not hold for many contents $p$ of appearance. In particular $\mathrm{A}(\mathrm{x}, \mathrm{A}(\mathrm{x}, \mathrm{p})$ ) entails $\mathrm{A}(\mathrm{x}, \mathrm{p})$. Moreover, access to objective (and therefore non-illusory) reality is by definition access by a subject, and it is therefore access marked by the subjective perspective. Hence it follows that subjectivity is not a sufficient condition for illusoriness. The problem is therefore determining whether there are experiences of temporal becoming which cannot be illusory. If it is found that even one single subjective experience of becoming is not illusory, the B-theoretical perspective is refuted.

The subjective experience of becoming can be described as follows:

$$
\mathrm{A}(\text { now, } \mathrm{Fa}) \wedge \mathrm{A}(\text { before, } \neg \mathrm{Fa}) \text {. }
$$

And, in general, with reference to any state of affairs $p$ :

$$
\mathrm{A}(\text { now, } \mathrm{p}) \wedge \mathrm{A}(\text { before }, \neg \mathrm{p}) \text {. }
$$

Note the indexical nature of the temporal reference. This seems indisputable. Appearing is appearance to the subject's consciousness. Consciousness is at the origin of the experience of time, whether it is illusory or not. Appearing to consciousness is therefore always an appearing in the now $(\mathrm{A}($ now,...$))$ or in the now that is past $(\mathrm{A}($ before,...$)$ or in the now that will be future $(A(a f t e r, \ldots))$. This does not rule out that one can say 'it appears to me on 16 April 2005 that ...'. This only implies that now $=16$ April 2005. Likewise with the other times: 'it appeared to me on 10 April 2005 that ...', 'it will appear to me on 20 April 2005 that ...'. As evident from even this brief outline, the logic to attribute to the appearance operator is exactly the logic which the A-theorists attribute to the actuality operator E. Even though the times of becoming are associated with an objective structure, what matters for A-theorists is the fact that the individual temporal worlds are actualized sequentially: that is, the fact that there exists a particular world $t$ (with $t=$ now) corresponding to the moment of actualization, and that as the now slides past, successive worlds are actualized according to the structure order of time. From the ontological-formal point of view, this means that for $\mathrm{A}$-theorists the operator $\mathrm{E}$ is not indicized. In other words, 
for A-theorists it is correct to write $\mathrm{E}(\mathrm{t}, \mathrm{p})$, and not $\mathrm{E}_{\mathrm{t}} \mathrm{p}$. Yet this logic is also the logic of appearance. It must be particularly so in the approach that I assume here: namely that the experience of becoming is internal to the world of appearings to consciousness. It would not even be illusory experience of becoming if it were not experience of the change (actualization in succession) of mental phenomena. Let us consider in detail the relation between the experience of becoming as an illusory phenomenon and the open character of the appearance operator (the appearance operator is not indicized). Let us therefore assume that we have an illusory experience of becoming. Thus we experience the change (actualization in succession) of mental phenomena. But this cannot come about unless the following law of simultaneity holds:

LS:

$$
\mathrm{E}\left(\mathrm{t}^{\prime}, \mathrm{A}(\mathrm{t}, \mathrm{p})\right) \rightarrow \mathrm{t}^{\prime}=\mathrm{t}
$$

according to which the instant of the actuality of the appearing coincides with the instant of appearing. But then:
$\mathrm{A}(\mathrm{t}, \mathrm{p}) \leftrightarrow \mathrm{A}_{\mathrm{t}} \mathrm{p}$
hypothesis per absurdum
$A(t, p)$ assumption
$A_{t} p$
by MP
$\mathrm{E}\left(\mathrm{A}_{\mathrm{t}} \mathrm{p}\right)$
def. $A_{t}$
$\forall \mathrm{t}^{\prime} \mathrm{E}\left(\mathrm{t}^{\prime}, \mathrm{A}_{\mathrm{t}} \mathrm{p}\right)$
law of implication EN
$\forall \mathrm{t}^{\prime} \mathrm{E}\left(\mathrm{t}^{\prime}, \mathrm{A}(\mathrm{t}, \mathrm{p})\right)$
substitution of the equivalents

But the result contradicts the above-mentioned law of simultaneity. Consequently:

$$
\mathrm{A}(\mathrm{t}, \mathrm{p}) \rightarrow \neg\left(\mathrm{A}(\mathrm{t}, \mathrm{p}) \leftrightarrow \mathrm{A}_{\mathrm{t}} \mathrm{p}\right) .^{2}
$$

2 The same result can be obtained by using the following weaker formulation of the EN law: $\mathrm{Ep}_{\mathrm{t}} \rightarrow \square \mathrm{p}_{\mathrm{t}}$. This is weaker than the original version because the actuality operator does not appear in the consequent, and the necessity operator is defined in the standard semantic manner. However, by setting $\mathrm{t}=$ now and maintaining the other assumptions, one obtains $\square \mathrm{A}$ (now,p), which is impossible. In fact: per absurdum let $A(t, p) \leftrightarrow A_{t} p$ and by assumption $A(t, p)$; thus by MP we have $A_{t} p$ and therefore $E\left(A_{t} p\right)$; yet for the weak version of $E N, \square A(t, p)$, and therefore, setting $\mathrm{t}=$ now, $\square \mathrm{A}($ now,p). 
Hence, the appearance operator is not indicized. Moreover, it obeys certain fundamental principles of epistemic logic. ${ }^{3}$ In particular, the following two axioms hold:

Axiom D: A(t,p) $\rightarrow \neg \mathrm{A}(\mathrm{t}, \neg \mathrm{p})$, briefly Ap $\rightarrow \neg \mathrm{A} \neg \mathrm{p}$

Axiom 4: $\mathrm{A}(\mathrm{t}, \mathrm{p}) \rightarrow \mathrm{A}(\mathrm{t}, \mathrm{A}(\mathrm{t}, \mathrm{p}))$, briefly $\mathrm{A}(\mathrm{t}, \mathrm{p}) \rightarrow \mathrm{A}(\mathrm{t}, \mathrm{Ap})$ or also Ap $\rightarrow$ AAp.

To conclude: the becoming of appearing is rightly formalizable as (3): $\mathrm{A}($ now, $\mathrm{p}) \wedge \mathrm{A}$ (before, $\neg \mathrm{p}$ ), or, because of Axiom D: $\mathrm{Ap} \rightarrow \neg \mathrm{A} \neg \mathrm{p}$ ), as:

(4) $\mathrm{A}($ now, $\mathrm{p}) \wedge \neg \mathrm{A}$ (before, $\mathrm{p})$.

But, now, let us ask: "What are the relationships between appearing and being?". The answer to this question implies the impossibility of B-theoretical account of phenomenal becoming. Indeed, there seem to be two essential bridge laws:

$\mathrm{LR}$ (reduction): $\mathrm{E}(\mathrm{t}, \mathrm{A}(\mathrm{t}, \mathrm{p})) \leftrightarrow \mathrm{E}(\mathrm{t}, \mathrm{Ap})$.

LC (correspondence between $A$ and $E): A(t, p) \leftrightarrow E(t, A(t, p))$; in short, for $\mathrm{LR}, \mathrm{A}(\mathrm{t}, \mathrm{p}) \leftrightarrow \mathrm{E}(\mathrm{t}, \mathrm{Ap})$.

Note 1: $\mathrm{LR}$ claims that $\mathrm{E}(\mathrm{t}, \mathrm{A}(\mathrm{t}, \mathrm{p}))$ is equivalent to $\mathrm{E}(\mathrm{t}, \mathrm{Ap})$. This is because the appearance operator is not indicized. For this reason, saying that the appearing of $p$ is actualized at time $t$ is the same as saying that at $t$ the appearing at $\mathrm{t}$ of $\mathrm{p}$ is actualized.

Note 2: LC claims that the appearing of the state of affairs $\mathrm{p}$ at time $\mathrm{t}$ coincides with the being actual at $t$ of that appearing. Instead, $A(t, p) \leftrightarrow$ $\mathrm{E}\left(\mathrm{t}, \mathrm{A}_{\mathrm{t}} \mathrm{p}\right)$ does not hold. Indeed, in order for $\mathrm{p}$ to appear in $\mathrm{t}$, it is not enough that the appearing-in-t be actual in $t$. Assume, in fact, $A(t, p) \leftrightarrow E\left(t, A_{t} p\right)$. But, necessarily $E\left(t, A_{t} p\right)$ (because $\forall t^{\prime} E\left(t^{\prime}, A_{t} p\right)$ ), while $A(t, p)$ may be contingent.

Note 3: The same result as the one in the previous note can be obtained using the law LS introduced above.

3 See in particular (Galvan 1991, 2006) and (Giordani 2002). 

$\mathrm{A}(\mathrm{t}, \mathrm{p}) \leftrightarrow \mathrm{E}\left(\mathrm{t}, \mathrm{A}_{\mathrm{t}} \mathrm{p}\right)$
hypothesis per absurdum
$\left.\mathrm{E}\left(\mathrm{t}, \mathrm{A}_{\mathrm{t}} \mathrm{p}\right)\right) \leftrightarrow \mathrm{A}_{\mathrm{t}} \mathrm{p}$
def. E
$\mathrm{A}(\mathrm{t}, \mathrm{p}) \leftrightarrow \mathrm{A}_{\mathrm{t}} \mathrm{p}$
by equivalence
$\mathrm{A}(\mathrm{t}, \mathrm{p})$
assumption
$A_{t} p$
by $\mathrm{MP}$
$\forall \mathrm{t}^{\prime} \mathrm{E}\left(\mathrm{t}^{\prime}, \mathrm{A}_{\mathrm{t}} \mathrm{p}\right)$
$\operatorname{def} \mathrm{A}_{\mathrm{t}}$ and law $\mathrm{EN}$
$\forall \mathrm{t}^{\prime} \mathrm{E}\left(\mathrm{t}^{\prime}, \mathrm{A}(\mathrm{t}, \mathrm{p})\right)$
substitution of the equivalents

But the result is against LS. Then

$$
\mathrm{A}(\mathrm{t}, \mathrm{p}) \rightarrow \neg\left(\mathrm{A}(\mathrm{t}, \mathrm{p}) \leftrightarrow \mathrm{E}\left(\mathrm{t}, \mathrm{A}_{\mathrm{t}} \mathrm{p}\right)\right)
$$

Nor does $A(t, p) \leftrightarrow E_{t}(A(t, p))$ hold, because $E_{t}(A(t, p))$ is equivalent to $A_{t} p$ and, as we know, $A_{t} p$ is not equivalent to $A(t, p)$.

Now, on the basis of the laws LC and LR, we are compelled to give an A-theoretic account of phenomenal becoming. In fact, on the basis of (4) we obtain:

$$
\begin{array}{ll}
\mathrm{E}(\mathrm{t}, \mathrm{A}(\mathrm{t}, \mathrm{p})) \wedge \neg \mathrm{E}\left(\mathrm{t}^{\prime}, \mathrm{A}\left(\mathrm{t}^{\prime}, \mathrm{p}\right)\right) & \text { for } \mathrm{LC} \\
\mathrm{E}(\mathrm{t}, \mathrm{Ap}) \wedge \neg \mathrm{E}\left(\mathrm{t}^{\prime}, \mathrm{Ap}\right) & \text { for } \mathrm{LR}
\end{array}
$$

which is an A-theoretic form of becoming.

\section{Discussion of a sceptical objection concerning the structure of phenomenal becoming}

The sceptic doubts that the original experience is:

(3) $\mathrm{A}($ now, $\mathrm{p}) \wedge \mathrm{A}$ (before, $\neg \mathrm{p})$

from which the phenomenon of consciential becoming immediately follows:

(4) $\mathrm{A}($ now, $\mathrm{p}) \wedge \neg \mathrm{A}$ (before, $\mathrm{p})$.

Instead of (3) the sceptic asserts that:

(3') $\mathrm{A}($ now, $\mathrm{p}) \wedge \mathrm{A}($ now, $\mathrm{A}($ before,$\neg \mathrm{p}))$ 
from which the phenomenon of consciential becoming cannot be immediately obtained. In fact, how do we know that the appearing of $\neg \mathrm{p}$ (and therefore the non-appearing of $\mathrm{p}$ ) becomes the appearing of p? Only because, says the sceptic, we now have a memory of what appeared to us, and memory may deceive us.

I want to prove that (4) can also be obtained-at least in a particular case-from ( $\left.3^{\prime}\right)$. The proof divides into two parts:

\section{Part 1}

We start from the original experience according to the sceptic: $A(n o w, p) \wedge$ $\mathrm{A}$ (now, $\mathrm{A}($ before, $\neg \mathrm{p})$ ). Then, by applying the axiom 4 to the first conjunct of preceding formula, we obtain $\mathrm{A}$ (now, $\mathrm{A}($ now, $\mathrm{p})$ ) $\wedge \mathrm{A}$ (now, $\mathrm{A}$ (before, $\neg p)$ ). Hence, by exportation of operator $A$ we have $A($ now, $A($ now, $p) \wedge$ $\mathrm{A}($ before, $\neg \mathrm{p})$ ) and then, by axiom $\mathrm{D}, \mathrm{A}$ (now, $\mathrm{A}($ now, $\mathrm{p}) \wedge \neg \mathrm{A}$ (before, $\mathrm{p})$ ). Briefly:

$$
\begin{array}{ll}
\mathrm{A}(\text { now }, \mathrm{p}) \wedge \mathrm{A}(\text { now, } \mathrm{A}(\text { before }, \neg \mathrm{p})) & \text { original experience } \\
\mathrm{A}(\text { now }, \mathrm{A}(\text { now }, \mathrm{p})) \wedge \mathrm{A}(\text { now }, \mathrm{A}(\text { before }, \neg \mathrm{p})) & \text { Axiom 4: Ap } \rightarrow \mathrm{AAp} \\
\mathrm{A}(\text { now, } \mathrm{A}(\text { now }, \mathrm{p}) \wedge \mathrm{A}(\text { before }, \neg \mathrm{p})) & \text { Exportation of } \mathrm{A} \\
\mathrm{A}(\text { now, } \mathrm{A}(\text { now }, \mathrm{p}) \wedge \neg \mathrm{A}(\text { before }, \mathrm{p})) & \text { Axiom } \mathrm{D}: \mathrm{Ap} \rightarrow \neg \mathrm{A} \neg \mathrm{p}
\end{array}
$$

In short, it follows from the original given that it appears to me that something appears to me that previously did not appear to me. Obviously, we have not yet reached the result because we have not obtained $A($ now, $p) \wedge$ $\neg \mathrm{A}$ (before, $\mathrm{p}$ ) — that is, the fact of becoming - but the appearance of it. The sceptic therefore says that this is an illusory appearing. The next part of the proof consists in showing that we cannot be totally deceived.

\section{Part 2}

Here, the starting point is the definition of doxastic error. As in the case of the belief operator in epistemic logic, we have an error situation (with respect to the appearance operator) if $A p \wedge \neg p$, i. e. if it appears that $p$ and $p$ is false. Now, as the conclusion to the first part of the proof we obtained that $\mathrm{A}$ (now, $\mathrm{A}$ (now, $\mathrm{p}) \wedge \neg \mathrm{A}$ (before, $\mathrm{p})$ ). The sceptic says that this is an illusory appearing. But this means that the content of the most external appearance operator is false, i.e. that $\neg(\mathrm{A}($ now, $\mathrm{p}) \wedge \neg \mathrm{A}($ before, $\mathrm{p}))$ is true. Hence, using the transformation rule from $\wedge$ to $\vee$, we obtain $\neg \mathrm{A}$ (now, $\mathrm{p}) \vee \mathrm{A}$ (before, $\mathrm{p}$ ). But it follows from the original given that $\mathrm{A}$ (now, $\mathrm{p}$ ); hence, through use 
of the disjunctive syllogism, $\mathrm{A}$ (before, $\mathrm{p}$ ). At this point, applying axiom 4 to the preceding formula and using the original given with axiom $\mathrm{D}$, we obtain $\mathrm{A}($ now, $\neg \mathrm{A}($ before, $\mathrm{p})) \wedge \mathrm{A}$ (before, $\mathrm{A}($ before, $\mathrm{p}))$. Finally, again applying axiom $\mathrm{D}$, we obtain $\mathrm{A}$ (before, $\mathrm{A}($ before, $\mathrm{p})) \wedge \neg \mathrm{A}($ now, $\mathrm{A}($ before, $\mathrm{p})$ ). Briefly:

$$
\begin{aligned}
& \neg(\text { A }(\text { now }, \mathrm{p}) \wedge \neg \mathrm{A}(\text { before }, \mathrm{p})) \\
& \neg \mathrm{A}(\text { now }, \mathrm{p}) \vee \mathrm{A}(\text { before }, \mathrm{p}) \\
& \mathrm{A}(\text { now } \mathrm{p}) \\
& \mathrm{A}(\text { before }, \mathrm{p}) \\
& \mathrm{A}(\text { now }, \neg \mathrm{A}(\text { before }, \mathrm{p})) \wedge \\
& \mathrm{A}(\text { before, } \mathrm{A}(\text { before }, \mathrm{p}))
\end{aligned}
$$$$
\mathrm{A}(\text { before, } \mathrm{A}(\text { before, } \mathrm{p})) \wedge
$$$$
\neg \mathrm{A}(\text { now, } \mathrm{A}(\text { before, } \mathrm{p}))
$$

Def. error $\operatorname{Tr} \wedge \vee$

from the original given by disjunctive syllogism

from the original given and Axiom 4: Ap $\rightarrow$ AAp from the preceding row

from Axiom D: Ap $\rightarrow \neg \mathrm{A} \neg \mathrm{p}$

Now, $\mathrm{A}$ (before, $\mathrm{A}$ (before, $\mathrm{p})) \wedge \neg \mathrm{A}$ (now, $\mathrm{A}$ (before, $\mathrm{p}$ )) (now it does not appear to me that previously $p$ appeared to me, while before the appearing of $p$ appeared to me) is indubitable experience of consciential becoming. Hence: for at least one state of affairs $\mathrm{p}$ of phenomenological nature (a state of appearing to the consciousness), it is certain that the reality of becoming is given: $\mathrm{A}($ before, $\mathrm{p})) \wedge \neg \mathrm{A}$ (now, $\mathrm{p}$ ), which is a variant of (4).

\section{Bibliography}

Craig, W.L. 2000a The Tensed Theory of Time. A Critical Examination, Dordrecht/Boston/London: Kluwer.

- 2000b The Tenseless Theory of Time. A Critical Examination, Dordrecht/ Boston/London: Kluwer.

Galvan, S. 1991 Logiche intensionali. Sistemi proposizionali di logica modale, deontica, epistemica, Milano: Angeli.

— “Tempo e realtà del divenire", Rivista di Filosofia Neoscolastica 97, 297320.

- 2006 "Logica epistemica", Enciclopedia Filosofica di Gallarate, Milano: Bompiani.

Giordani, A. 2002 Teoria della fondazione epistemica, Milano: Angeli.

Le Poidevin, R. 1998 Questions on Time and Tense, Oxford: Clarendon Press. 
Lewis, D. 1983 Philosophical Papers I, New York-Oxford: Oxford University Press.

- 1986a On the Plurality of Worlds, Oxford: B. Blackwell.

- 1986b Philosophical Papers II, New York-Oxford: Oxford University Press.

Loux, M. (ed.) 1979 The Possible and the Actual. Readings in the Metaphysics of Modality, Ithaca: Cornell University Press.

- 1997 Metaphysics. A Contemporary Introduction, London: Routledge.

Lowe, E.J. 1998 The Possibility of Metaphysis: Substance, Identity, and Time, Oxford: Oxford University Press.

- 2002 A Survey of Metaphysics, Oxford: Clarendon Press.

McTaggart, J.M.E. 1908 “The Unreality of Time”, Mind 17, 457-74.

Mellor, D.H. 1981 Real Time, Cambridge: Cambridge University Press.

- 1998 Real Time II, London: Routledge.

Merricks, T. 2001 Objects and Person, Oxford: Clarendon Press.

Oaklander, L.N. 1992 "Temporal Passage and Temporal Parts", Nous 26, 79-84.

- 2004 The Ontology of Time, New York: Prometheus Books.

Oaklander, L.N. and Smith, Q. (eds.) 1994 The New Theory of Time, New Haven, CT: Yale University Press.

Pauri, M. 1996 “Oggettività e realtà", in Minazzi F. (ed.), L'oggettività della conoscenza scientifica, Milano: Angeli.

Plantinga, A. 1974 The Nature of Necessity, Oxford: Oxford University Press.

Runggaldier, E. and Kanzian, C. 1998 Grundprobleme der Analytischen Ontologie, Paderborn: Schöningh.

Schlesinger, G. 1983 Metaphysics, Totowa, N.J: Barnes and Noble.

Seddom, K. 1987 Time, A Philosophical Treatment, New York: Croom Helm.

Severino, E. (1995) Essenza del nichilismo. Nuova edizione ampliata, Milano: Adelphi Edizioni.

Smith, Q. 1993 "Change", in Kim, J. and Sosa, E. (eds.), A Companion to Metaphysics, Cambridge MA: Basil Blackwell.

- 1993 Language and Time, New York-Oxford: Oxford University Press.

Smith, Q. and Oaklander, L.N. (eds) 1995 Time, Change and Freedom. An Introduction to Metaphysics, London-New York: Routledge.

Smith, Q. and Jokic, A. (eds) 2002 Time, Tense and Reference, Cambridge MA: MIT Press. 
Swinburne, R. 1990 “Tensed Facts", American Philosophical Quarterly 27, $117-130$.

Van Inwagen, P. 1993 Metaphysics, Westview Press, Boulder Col.

Van Inwagen, P. and Zimmermann, D.W. (eds.) 1998 Metaphysics. The Big Questions, Oxford: B. Blackwell, Part One, 1-257.

Varzi, A.C. 2001 Parole, oggetti, eventi, e altri argomenti di metafisica, Carocci: Roma.

- 2003 "Entia successiva", Rivista di Estetica 22, 139-158.

- 2003 "Riferimento, predicazione, e cambiamento", in Bianchi, C. and Bottani A. (eds.), Significato e ontologia, Milano: Angeli, 221-249. 